\title{
Analysis of pressure relief and outburst prevention effect and mining depth effect of floor roadway in single serious outburst coal seam
}

\author{
Guohong Chen ${ }^{1,2, a}$ \\ ${ }^{1}$ Chongqing Research Institute CO., Ltd of China Coal Technology Engineering Group, Chongqing, China \\ ${ }^{2}$ National Key Laboratory of Gas Disaster Monitoring and Emergency Technology, Chongqing, China
}

\begin{abstract}
In order to solve the serious problem of single serious outburst coal seam gas disaster, based on the gas geological conditions of Jiangxi Fengcheng Qujiang company, theoretical analysis, numerical simulation, field test and other comprehensive research methods were used to analyze the partition fracture law of roadway surrounding rock under different mining depth conditions. The results show that: under the conditions of high ground stress, high temperature and other environmental conditions, the radius of pressure relief loose circle of surrounding rock of roadway is significantly increased, and it is significantly larger than that of shallow part. In the deep area of - $800 \mathrm{~m}$ elevation, the distance between floor roadway and coal seam is optimized to be $12 \sim 15 \mathrm{~m}$. The field test results show that the original permeability coefficient of overlying coal seam of floor roadway increases by 55.74 times, and the pressure relief effect is good.
\end{abstract}

\section{Mine overview}

Fengcheng Qujiang Coal Development Co., Ltd. (hereinafter referred to as "Qujiang company") is one of the main production mines of Fengcheng branch of Jiangxi Coal Industry Group Co., Ltd. The designed production capacity of the mine is $900000 \mathrm{t} / \mathrm{a}$, and the approved production capacity is $600000 \mathrm{t} / \mathrm{a}$. The single $\mathrm{B}_{4}$ coal seam is mined, and the current mining level is $-850 \mathrm{~m}$ level. The measured maximum gas pressure and gas content reach $9.2 \mathrm{MPa}$ and $18.53 \mathrm{~m}^{3} / \mathrm{t}$ respectively, which leads to serious gas disaster. $\mathrm{B}_{4}$ coal seam is well developed and stable, with a thickness of $1.0 \sim 3.87 \mathrm{~m}$, an average thickness of $2.16 \mathrm{~m}$, and a dip angle of $12^{\circ} \sim 14^{\circ}$, the recoverable coefficient is $2.4 \%$. The north wing of Qujiang syncline is generally $2.0 \sim 3.5 \mathrm{~m}$ thick with simple structure. In most areas, there is a layer of gangue with a thickness of $0.05 \sim 0.50 \mathrm{~m}$. The whole area is basically minable and stable coal seam with good coal quality, ranging from lean coal to lean coking coal.

In order to improve the regional outburst prevention effect, the floor rock roadway is arranged at an appropriate position under the outburst coal seam, and the floor rock roadway is used for pressure relief combined with drilling through the seam to extract the strip gas from the coal roadway. The core is to use the pressure relief effect of the mining roadway to release the pressure and extract the gas from the coal roadway strip, so as to eliminate or reduce the outburst elastic energy and gas potential of the coal roadway strip. At the same time, it is necessary to ensure the safety of floor roadway driving. With the increase of mining depth, the pressure relief effect of floor roadway in different mining depth is different. Therefore, based on the site conditions of Qujiang company and the partition fracture law of roadway surrounding rock, this paper studies the partition fracture law of floor roadway surrounding rock under different buried depth conditions, so as to determine the reasonable location of floor roadway under different buried depth conditions.

\section{Analysis on fracture mechanism of surrounding rock zone in deep roadway}

The ground stress level of deep mining is high, and the surrounding rock is temporarily in elastic state at the moment of roadway excavation. The surrounding rock mass appears stress concentration and brittle tensile fracture failure, forming the surrounding pressure relief area, as shown in Figure 1 (a). Due to the high horizontal in-situ stress and rheological property of coal and rock in the deep, the stress in the peak area of stress concentration exceeds the strength of rock mass and is destroyed. The elastic energy is further released, so that the boundary between the plastic zone and the elastic zone gradually moves back, and the plastic zone gradually develops to the deep, as shown in Figure 1 (b), forming a ring continuous fracture. Because of the stress concentration, the surrounding rock outside the annular continuous joint will appear elastic brittle tensile fracture, as shown in Figure 1 (c). In this way, the elastic brittle tensile fracture and the plastic brittle tensile fracture will occur repeatedly. The annular continuous joint makes the surrounding rock produce alternate failure and non failure areas, that is,

\footnotetext{
a Corresponding author: 79513701@qq.com
} 
zonal fracture phenomenon. This phenomenon continues until the maximum radial tensile strain produced by load in surrounding rock is less than the ultimate tensile strain of surrounding rock, as shown in Figure 1 (d). Therefore, under the deep high stress environment, the coal and rock mass are in the state of post peak characteristics, and there may be complex stress zones in the surrounding rock of the roadway. Under certain conditions, sometimes the expansion zone and compression zone alternately appear in the surrounding rock of the roadway, and its geometric size (width) increases by an equal ratio sequence, resulting in regional fracture ([1-2]). The peak stress of surrounding rock of roadway weakens and the width of pressure relief zone increases significantly, as shown in Figure 2.

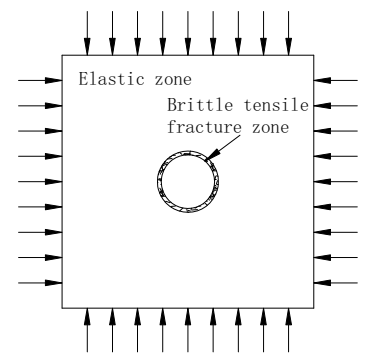

(a)

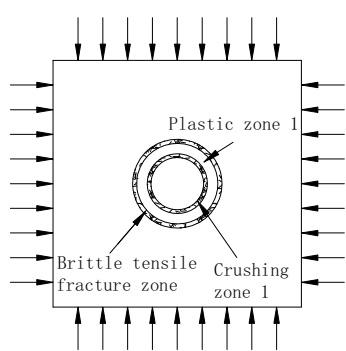

(c)

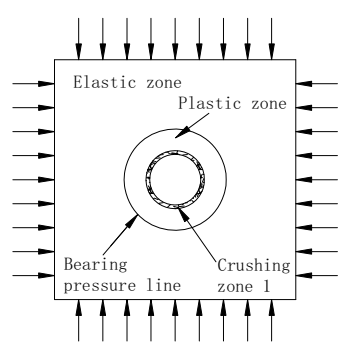

(b)

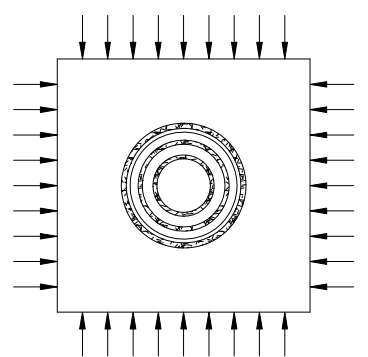

(d)
Figure 1. Evolution process of zonal fracture of surrounding rock in deep roadway

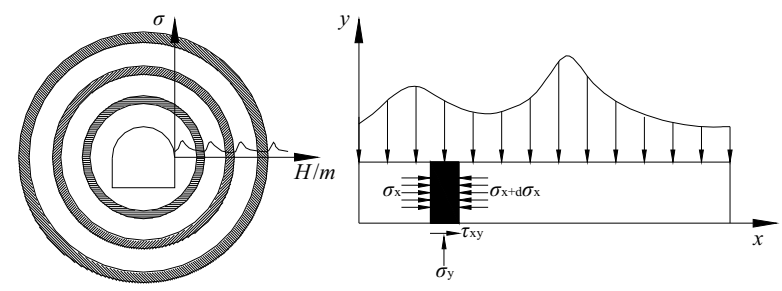

Figure 2. Distribution diagram of non unimodal stress in surrounding rock zone failure of roadway

In the stage of Figure 1 (b), because the radial tensile strain at the support pressure line of the shallow roadway can not reach the maximum radial tensile strain, the plastic strengthening zone can fully support the surrounding rock pressure, that is, there is only one fracture zone and one complete zone, which will not produce zonal fracture phenomenon, and it is only the first fracture zone of the deep roadway zonal fracture. Therefore, the pressure relief radius of surrounding rock of shallow roadway is much smaller than that of deep roadway.

Generally, there are several fracture zones in deep roadway. The pressure relief radius of roadway is from the roadway wall to the outer boundary of the outermost fracture zone. Assuming that the outermost fracture zone is $\mathrm{I}$, the expression of the inner boundary of the i-th fracture zone is as follows ([3-5]):

$$
R_{i}^{i}=R_{i-1}^{e} \times\left[\frac{v(3-2 v)(1+v) p_{0}+(1-v) \sigma_{t}}{\left(p_{i-1}^{e}-\sigma_{t}\right)(1-v)^{2}}\right]^{\frac{1-\sin \varphi}{2 \sin \varphi}}
$$

The expression of the outer boundary of the i-th fracture zone (pressure relief radius of roadway) is as follows:

$$
R_{i}^{e}=R_{i}^{i} \times\left[\frac{3}{-12(3-2 v)\left(1-v^{2}\right) \sigma_{i} / p_{0}-v^{2}(2 v-1)^{2}}\right]^{\frac{1}{4}}
$$

Where, the subscripts of $R$ and $P$ denote the number of the fracture zone, the superscript $i$ denotes the inner boundary of the fracture zone, and the superscript $e$ denotes the outer boundary of the fracture zone; $v$ Is Poisson's ratio of material; $P$ is the original rock stress; $P_{1}=0$ 。

To sum up, the width of pressure relief zone near roadway surrounding rock is different between shallow and deep mining due to the large difference of in-situ stress. With high in-situ stress level in deep mining, zonal fracture may be formed near the surrounding rock of roadway, and the width of pressure relief zone increases significantly.

\section{Influence of mining depth on pressure relief effect of floor roadway}

The vertical distance from the fixed coal floor roadway to the gateway $H=15 \mathrm{~m}$, the horizontal distance between the gateway and the floor roadway $b=0 \mathrm{~m}$, and the coal seam dip angle is $0^{\circ}$, Lateral pressure coefficient $\lambda=5$, change the coal seam depth $H$. When the buried depth $h$ of coal seam is $600 \mathrm{~m}, 800 \mathrm{~m}$ and $1000 \mathrm{~m}$ respectively, the general law of variation of stress, deformation and failure characteristics of surrounding rock with the buried depth $h$ is studied.

\section{1 variation law of roadway surrounding rock stress with buried depth}

When the burial depth $\mathrm{h}$ changes, the distribution of stress change of surrounding rock of floor roadway is shown in Figure 3 and Figure 4. The variation curve of surrounding rock stress of floor roadway with buried depth $\mathrm{h}$ is shown in Figure 5.

It can be seen from Figure 3 to Figure 5 that with the increase of roadway buried depth, the peak values of vertical stress and shear stress of surrounding rock of roadway increase approximately according to the linear law, the range of concentration area increases continuously, the position of peak point gradually moves to the depth of surrounding rock of roadway, and the position of peak point is within $1 \sim 4 \mathrm{~m}$ away from roadway side. When the buried depth of roadway increases from 
$600 \mathrm{~m}$ to $1000 \mathrm{~m}$, the peak vertical stress increases from $33.5 \mathrm{MPa}$ to $45 \mathrm{MPa}$, with an increase of $64.2 \%$, and the peak shear stress increases from $8.64 \mathrm{MPa}$ to $11.4 \mathrm{MPa}$, with an increase of $31.9 \%$.

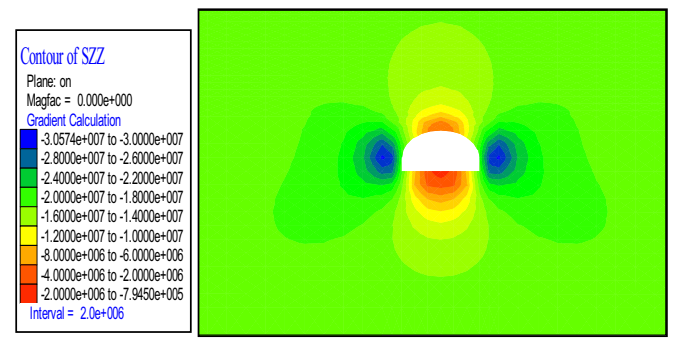

(a) Buried depth $600 \mathrm{~m}$

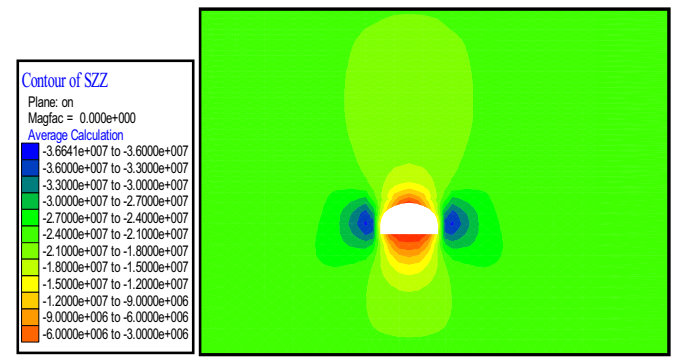

(b) Buried depth $800 \mathrm{~m}$

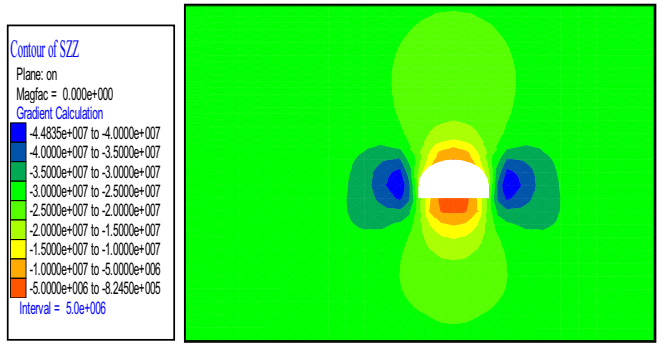

(c) Buried depth $1000 \mathrm{~m}$

Figure 3. Distribution law of vertical stress in surrounding rock of floor roadway with different buried depth

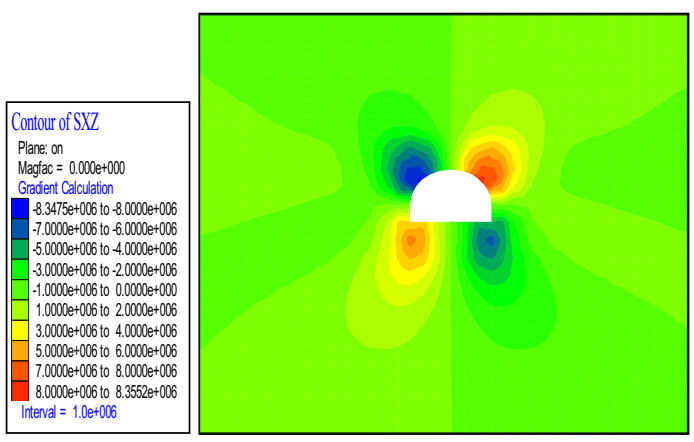

(a) Buried depth $600 \mathrm{~m}$

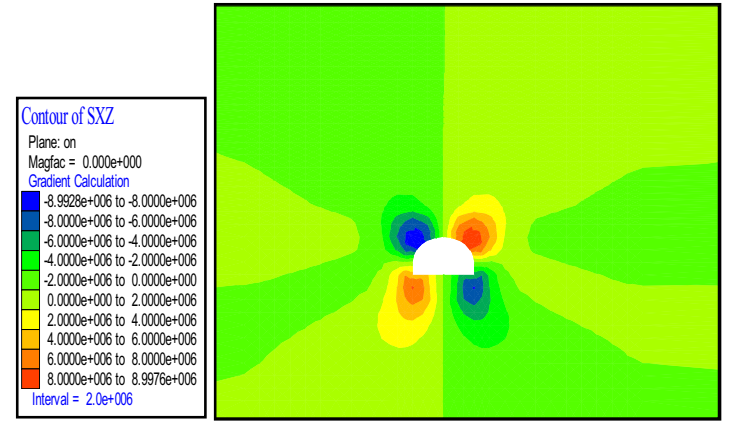

(b) Buried depth $800 \mathrm{~m}$

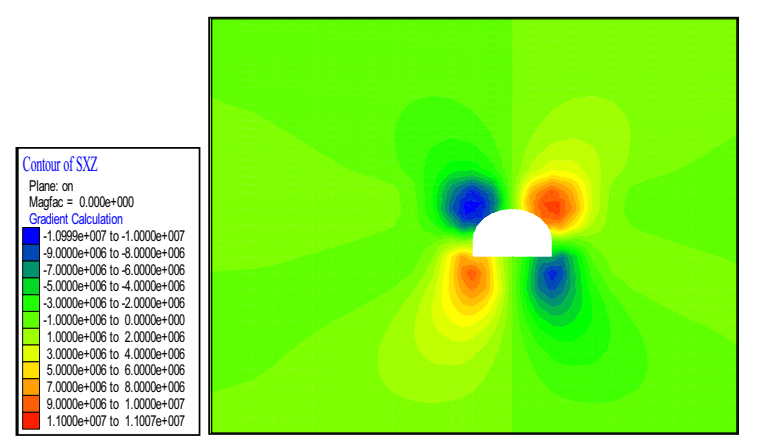

(c) Buried depth $1000 \mathrm{~m}$

Figure 4. Distribution law of shear stress of surrounding rock in different buried depth floor roadway

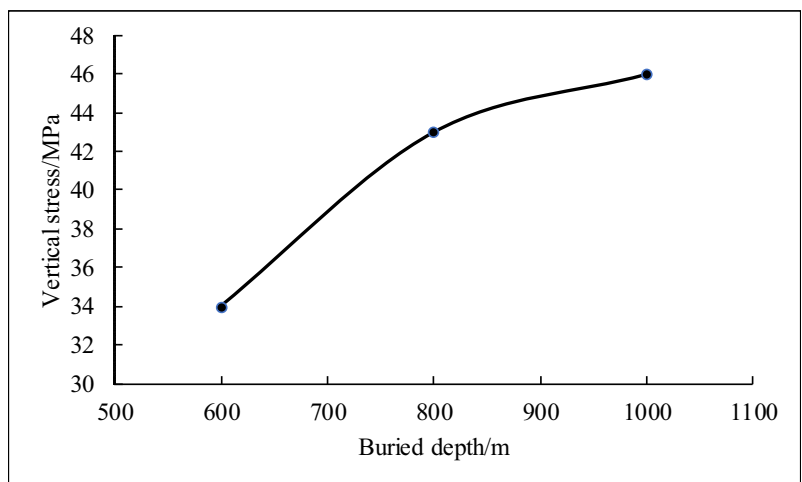

(a) Vertical stress

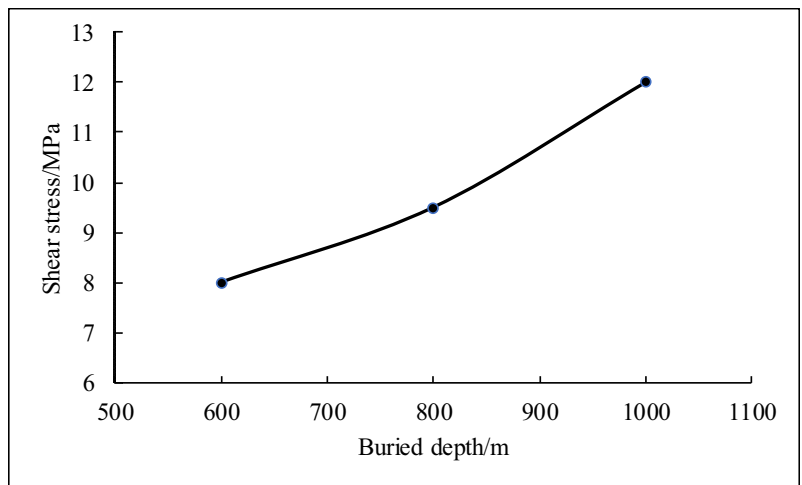

(b) Shear stress

Figure 5. Variation curve of surrounding rock stress of floor roadway with buried depth

With the increase of stress concentration, a part of the surrounding rock of the roadway goes into plastic state, the deformation of surrounding rock increases rapidly, and the state of surrounding rock tends to be complex.

\subsection{The law of plastic zone and displacement of roadway surrounding rock changing with buried depth Field engineering application}

The variation curve of plastic zone and displacement of surrounding rock of floor roadway with buried depth is shown in Figure 6.

It can be seen from Figure 6 that the plastic zone and displacement deformation appear in the roof, floor and left and right sides after floor roadway excavation, and the size of the plastic zone is basically the same, but the plastic zone of the roof is slightly larger than that of the 
floor and left and right sides. The order of surrounding rock displacement is roof, floor, left side and right side. With the increase of buried depth, the plastic zones of roof and floor, left and right sides of floor roadway are gradually increasing, and the increase size is basically similar. The displacement of roof, floor and left and right sides of floor roadway increases gradually, and the increase of roof and floor is greater than that of left and right sides. Therefore, with the increase of buried depth, the pressure relief degree of floor roadway increases gradually.

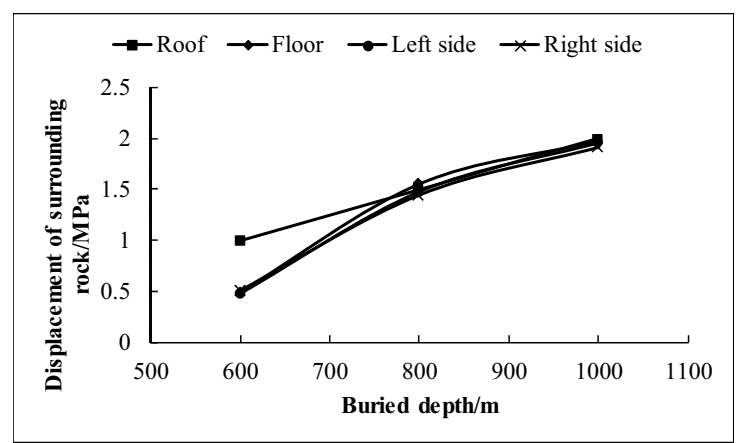

(a) Plastic zone of surrounding rock

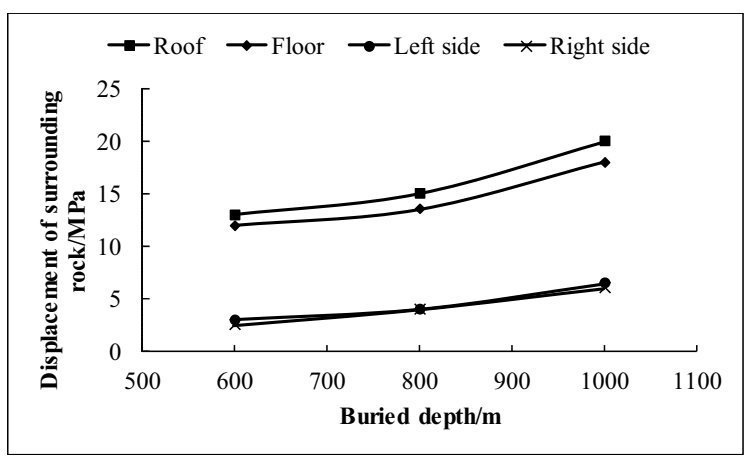

(b) Displacement of surrounding rock

Figure 6. Variation curve of plastic zone and displacement of surrounding rock of floor roadway with buried depth

It can be seen from the above analysis that with the increase of coal seam buried depth, the vertical stress and shear stress of roadway surrounding rock gradually increase, the plastic zone and deformation of roadway surrounding rock gradually increase, and the pressure relief degree of floor roadway roof gradually increases. Therefore, under the condition of shallow mining, the distance between the floor roadway and the overlying coal seam can be appropriately reduced to achieve the optimal extraction effect. Under the condition of deep mining, the distance between floor roadway and overlying coal seam can be appropriately increased while ensuring the thickness of safe rock pillar. In the shallow area of $-800 \mathrm{~m}$ elevation, the distance between floor roadway and coal seam is optimized to be $10 \sim 12 \mathrm{~m}$. In the deep area of $800 \mathrm{~m}$ elevation, the distance between floor roadway and coal seam is optimized to be $12 \sim 15 \mathrm{~m}$.

\section{Field engineering application}

Through the investigation on the effect of pressure relief and outburst prevention of floor rock roadway in 805 gateway of the mine, the roadway is located at the elevation of $-800 \mathrm{~m}$. The investigation results show that the deformation and failure of the surrounding rock of the floor rock roadway is obvious, and the maximum deformation of the surrounding rock displacement is $3.7 \mathrm{~cm}$. It is observed that the surrounding rock of the floor rock roadway has zonal fracture phenomenon. The original permeability coefficient of the strip coal seam in the coal roadway to be excavated increases by 55.74 times, and the initial gas flow of the borehole is obviously larger than that of the original coal seam, and the maximum is 16.52 times of that of the original coal seam. The effect of pressure relief and permeability increase of floor rock roadway is obvious.

\section{Conclusion}

(1) Based on the elasto-plastic rheological theory of the surrounding rock of floor roadway, it is analyzed that the surrounding rock of roadway may produce zonal fracture under the conditions of high ground stress and high temperature in deep coal mine, and the radius of pressure relief loose circle of surrounding rock of roadway increases significantly, which is significantly larger than that in shallow coal mine.

(2) The results of numerical simulation show that with the increase of mining depth, the pressure relief range of floor roadway increases, and the distance between floor roadway and coal seam is optimized to be $12 \sim 15 \mathrm{~m}$ in the area with $-800 \mathrm{~m}$ elevation.

(3) The field test results show that the original permeability coefficient of overlying coal seam in floor roadway increases by 55.74 times, and the pressure relief effect is good.

\section{References}

1. Meng X Z, Wang Z H, Chen G H, et al. Pressure relief and outburst prevention technology of coal roadway driving in deep single serious outburst coal seam [J]. Coal science and technology, 2016, 44 (012): 75-80.

2. Cao J J, Wang Z H, Yang H M. Study on outburst prevention technology of strip pre driving floor rock roadway in deep coal roadway [J]. Mining safety and environmental protection, 2019,46 (06): 14-19.

3. Ren H F. Failure mechanism of lower floor and surrounding rock control technology of roadway in goaf of close seam group [D]. Xi'an University of science and technology, 2016.

4. Feng F. High stress soft rock roadway pressure relief and secondary support technology [D]. China University of mining and technology, 2016.

5. Wang Z H, Sun L, Yuan B Q. Numerical simulation study on reasonable spatial position of pressure relief floor rock roadway $[\mathrm{J}]$. Coal technology, 2015, 11 (11): 88-91. 